\title{
Signal recognition particle protein 19 is imported into the nucleus by importin 8 (RanBP8) and transportin
}

\author{
Kellie A. Dean ${ }^{1,2, *}$, Oliver von Ahsen², Dirk Görlich ${ }^{2}$ and Howard M. Fried ${ }^{1, \neq}$ \\ 1Department of Biochemistry and Biophysics, The University of North Carolina at Chapel Hill, Chapel Hill, NC 27599, USA \\ 2Zentrum für Molekulare Biologie der Universität Heidelberg, Im Neuenheimer Feld 282, D-69120 Heidelberg, Federal Republic of Germany \\ *Present address: Department of Genetics, Duke University Medical Center, Box 3657, Durham, NC 27710, USA \\ ‡Author for correspondence (e-mail: refried@email.unc.edu) \\ Accepted 18 June 2001 \\ Journal of Cell Science 114, 3479-3485 @ The Company of Biologists Ltd
}

\section{SUMMARY}

The signal recognition particle (SRP) is a cytoplasmic RNA-protein complex that targets proteins to the rough endoplasmic reticulum. Although SRP functions in the cytoplasm, RNA microinjection and cDNA transfection experiments in animal cells, as well as genetic analyses in yeast, have indicated that SRP assembles in the nucleus. Nonetheless, the mechanisms responsible for nuclearcytoplasmic transport of SRP RNA and SRP proteins are largely unknown. Here we show that the $\mathbf{1 9} \mathrm{kDa}$ protein subunit of mammalian SRP, SRP19, was efficiently imported into the nucleus in vitro by two members of the importin $\beta$ superfamily of transport receptors, importin 8 and transportin; SRP19 was also imported less efficiently by several other members of the importin $\beta$ family. Although transportin is known to import a variety of proteins, SRP19 import is the first function assigned to importin 8. Furthermore, we show that a significant pool of endogenous SRP19 is located in the nucleus, as well as the nucleolus. Our results show that at least one mammalian SRP protein is specifically imported into the nucleus, by members of the importin $\beta$ family of transport receptors, and the findings add additional evidence for nuclear assembly of SRP.

Key words: Importin, Nuclear transport, Nucleolus, Signal recognition particle, SRP19

\section{INTRODUCTION}

The signal recognition particle (SRP) is a ubiquitous ribonucleoprotein (RNP) complex that targets nascent secretory polypeptides from the ribosome into the endoplasmic reticulum in eukaryotic cells and from the ribosome to the plasma membrane in prokaryotic cells (Luirink and Dobberstein, 1994; Lütcke, 1995). Vertebrate SRP comprises a 300-nucleotide RNA molecule, SRP RNA and six polypeptides designated SRP9, SRP14, SRP19, SRP54, SRP68 and SRP72. All of the components of SRP, including SRP RNA, participate directly in the overall protein targeting process (Batey et al., 2000; Peluso et al., 2000). Although a considerable amount is known about the structure and function of SRP, the questions of how and where SRP assembles in the cell have attracted attention only recently. As the RNA molecule is synthesized in the nucleus and the particle functions in the cytoplasm, it is possible that SRP proteins either assemble with the RNA in the cytosol or that they enter the nucleus, bind to the RNA and exit from the nucleus complexed with SRP RNA. An early suggestion concerning the location of SRP assembly came from RNA nuclear injection experiments; a mutant SRP RNA deficient in binding SRP9 and SRP14 was also impaired in export, suggesting that at least these two SRP proteins enter the nucleus to assemble with SRP RNA as a prerequisite for SRP RNA export (He et al., 1994). Politz et al. (Politz et al., 2000) reported that GFP-fusions of SRP19, SRP68 and SRP72 expressed in transiently transfected animal cells localized to some extent within the nucleus and the nucleolus; in situ hybridization revealed endogenous SRP RNA in the nucleolus as well. Similarly, Ciufo and Brown (Ciufo and Brown, 2000) and Grosshans et al. (Grosshans et al., 2001) detected all but one of the yeast SRP proteins to some extent in the nucleus and nucleolus; furthermore, analysis of mutants lacking individual SRP proteins showed that most are required for nuclear export of SRP RNA. Thus, it appears that SRP assembles at least in part in the nucleus and/or nucleolus. However, the mechanisms by which SRP proteins are imported into the nucleus and SRP is exported from the nucleus largely remain to be determined. Ciufo and Brown (Ciufo and Brown, 2000) and Grosshans et al. (Grosshans et al., 2001) found that nuclear export of yeast SRP RNA requires Xpo1p (CRM1 in animal cells), a transport receptor known to have numerous substrates (Görlich and Kutay, 1999; Nakielny and Dreyfuss, 1999; Yoneda et al., 1999); still, neither group has identified the yeast SRP component(s) that serves as the ligand for Xpo1p. Lastly, the genetic analysis by Grosshans et al. (Grosshans et al., 2001) has implicated the transport receptors Pse1p and Kap123p/Yrb4p in nuclear import of yeast SRP proteins.

Nuclear-cytoplasmic transport is largely mediated by the importin $\beta$ family of nuclear transport receptors (Görlich and Kutay, 1999; Nakielny and Dreyfuss, 1999). These transport receptors bind cargo molecules (proteins, RNAs and RNAprotein complexes) in either the nucleus or cytoplasm, translocate with their cargo through nuclear pore complexes (NPC), release their cargo in the opposite compartment and finally return to the original compartment. All of the importin 
$\beta$ family members possess an N-terminal domain that binds RanGTP (Görlich et al., 1997). It is the receptor's interaction with Ran, a Ras-related GTPase, that controls the binding and release of cargo. Receptors that carry cargo into the nucleus are termed importins. Importins bind their cargo in the absence of RanGTP in the cytoplasm and dissociate from cargo in the presence of RanGTP in the nucleus. Exportins such as Xpo1p/CRM1 carry cargo out of the nucleus; they have weak affinity for their cargo in the absence of RanGTP but simultaneous binding of RanGTP in the nucleus dramatically increases the affinity between exportins and their respective cargoes. The different responses to RanGTP exhibited by importins and exportins are controlled by a RanGTP gradient established across the nuclear envelope (Görlich and Kutay, 1999).

In this report, we examined the question of how mammalian SRP proteins enter the nucleus, using SRP19 as an example. SRP19 directly bound and was efficiently imported into nuclei in vitro by two members of the importin $\beta$ family of transport receptors, importin 8 and transportin. SRP19 also bound to several other members of the importin $\beta$ family of transport receptors. However, compared to transportin and importin 8 , these other receptors were less efficient in promoting in vitro nuclear import of SRP19. Transportin is a well-characterized importin $\beta$-like transport factor whose cargoes include hnRNP proteins (Pollard et al., 1996; Fridell et al., 1997; Siomi et al., 1997) and ribosomal proteins (Jäkel and Görlich, 1998). Prior to this study, no cargo had been identified for importin 8 (previously known as RanBP8) (Görlich et al., 1997). Furthermore, we found that SRP19 localizes to the nucleoli during in vitro import assays and an anti-SRP19 antibody revealed a considerable amount of endogenous SRP19 in the nucleus and the nucleolus in vivo. These findings show that for at least one mammalian SRP protein, nuclear import is an authentic process, mediated by members of the importin $\beta$ family of transport receptors. Our results add additional evidence for nuclear assembly of SRP.

\section{MATERIALS AND METHODS}

\section{Antibodies}

The following antibodies have been described previously: antiimportin $\beta$ (Görlich et al., 1995), anti-importin 5 (RanBP5) (Jäkel and Görlich, 1998), anti-importin 7 (RanBP7) (Görlich et al., 1997) and anti-TRAP $\alpha$ (translocon-associated protein) (Görlich et al., 1990). Antibodies against peptides derived from the C-terminus of human importin 8 (RanBP8) and human CRM1 were raised in rabbits. The anti-SRP19 antibody was raised against the recombinant protein described below. All polyclonal sera were used after affinity purification. A monoclonal antibody against fibrillarin was a gift of T. Pederson (University of Massachusetts, Worcester, MA).

\section{Immunocytochemistry}

Endogenous SRP19 in HeLa cells was detected by indirect immunofluorescence followed by confocal microscopy. HeLa cells grown on coverslips were washed briefly in phosphate-buffered saline (PBS) and fixed with $100 \%$ acetone or $4 \%$ paraformaldehyde. Paraformaldehyde-fixed cells were permeabilized with $0.2 \%$ Triton X-100 in PBS. After a blocking step, primary antibodies were applied and incubated with the fixed cells for 1 hour in a humid chamber. Following extensive washing, primary antibodies were detected using either donkey anti-rabbit (Amersham) or sheep anti-mouse (Sigma) fluorescently labeled secondary antibodies. All incubations were at room temperature.

\section{Recombinant protein expression and purification}

The following proteins were expressed in E. coli BLR/Rep4 and purified as described previously: Xenopus importin $\alpha$ (Görlich et al., 1994); human importin $\beta$ (Görlich et al., 1996); Ran, NTF2, RanBP1 and Rna1p (Kutay et al., 1997); RanQ69L[GTP] (Görlich et al., 1997) and transportin (Izaurralde et al., 1997); importin 5 (RanBP5) (Jäkel and Görlich, 1998) and importin 7 (RanBP7) (Jäkel and Görlich, 1998). Importin 8 was expressed with an N-terminal 2z-tag (IgGbinding domain from Staphylococus aureas protein A) and a Cterminal his-tag (Görlich et al., 1997) and purified on nickel-NTA agarose (Qiagen) followed by precipitation with ammonium sulfate (33\% saturation) and chromatography on Superdex 200 (Pharmacia). Human ribosomal protein L23a was expressed as a fusion with $\mathrm{N}$ terminal z tags as previously described (Jäkel and Görlich, 1998); 2zrpL23a was used in binding assays, whereas 4z-rpL23a was used as a substrate in import assays. Human SRP19 was expressed in E. coli BL21(DE3) with an N-terminal his-tag (Henry et al., 1997) or as an $\mathrm{N}$-terminal his-tagged fusion to gluathione $\mathrm{S}$ tranferase (GST); expression vector was obtained from Young and Gautel (Young and Gautel, 2000). Human SRP19 was also expressed in E. coli BLR/Rep4 with N-terminal $2 \mathrm{z}$ tags and a C-terminal his-tag. Disruption of cells and purification of $\mathrm{HIS}_{6}$-SRP19, GST-SRP19, and 2z-SRP19 on nickel agarose was in the presence of $1 \mathrm{M}$ lithium chloride.

\section{Binding assays}

HeLa cell extract: 2z-rpL23a and 2z-SRP19 were immobilized on IgG-sepharose 4B (Pharmacia) at approximately $2 \mathrm{mg} / \mathrm{ml}$ in $50 \mathrm{mM}$ Tris- $\mathrm{HCl}, \mathrm{pH} 7.5,200 \mathrm{mM} \mathrm{NaCl}$ and $5 \mathrm{mM} \mathrm{MgCl}_{2}$. For each binding reaction, $20 \mu \mathrm{l}$ of the affinity matrix with either pre-bound $\mathrm{rpL} 23$ or SRP19 was rotated for 4 hours at $4^{\circ} \mathrm{C}$ with $500 \mu \mathrm{l}$ of HeLa cell extract. The beads were recovered by gentle centrifugation and washed extensively with binding buffer. Bound proteins were eluted with $1.5 \mathrm{M} \mathrm{MgCl}_{2}, 50 \mathrm{mM}$ Tris- $\mathrm{HCl}, \mathrm{pH} 7.5$, precipitated with $90 \%$ isopropanol (final concentration), resuspended in SDS sample buffer and analyzed by SDS PAGE.

Recombinant transport receptors: a GST-SRP19 fusion protein was bound to glutathione-sepharose (Pharmacia) for 1 hour at $4^{\circ} \mathrm{C}$ in binding buffer (50 mM Tris-HCl, pH 7.5, $0.1 \mathrm{M} \mathrm{NaCl}, 5 \mathrm{mM} \mathrm{MgCl} 2$ ), washed twice in the same buffer containing $1.0 \mathrm{M} \mathrm{NaCl}$, and then equilibrated with binding buffer. Transport receptors at $1.5 \mu \mathrm{M}$ concentration were preincubated for 30 minutes at $4{ }^{\circ} \mathrm{C}$ in binding buffer containing $0.5 \mathrm{mM}$ GTP, $0.5 \mathrm{mM}$ ATP, $10 \mathrm{mM}$ creatine phosphate and $50 \mu \mathrm{g} / \mathrm{ml}$ creatine kinase, with or without $10 \mu \mathrm{M}$ RanQ69L. Transport receptor samples were then added to $20 \mu \mathrm{l}$ of GST-SRP19 matrix and incubated for 4 hours at $4^{\circ} \mathrm{C}$ in binding buffer. The final concentration of GST-SRP19 per binding reaction was approximately $3 \mu \mathrm{M}$. The resin was washed four times with binding buffer and bound material eluted with SDS sample buffer and analyzed by SDS-PAGE.

\section{Preparation of labeled recombinant import substrates}

The preparation of fluorescent 4z-rpL23a has been described (Jäkel and Görlich, 1998). Fluorescent labeling of HIS6-SRP19 was with Alexa $594 \mathrm{C}_{5}$ malemide (Molecular Probes) in $50 \mathrm{mM}$ potassium phosphate, $\mathrm{pH} 7.2,250 \mathrm{mM} \mathrm{NaCl}$. Protein was separated from free label on a Sephadex G25 column (Pharmacia) equilibrated in $50 \mathrm{mM}$ potassium phosphate, $\mathrm{pH} 7.2,250 \mathrm{mM} \mathrm{NaCl}$.

\section{Nuclear import assays}

Permeabilized HeLa cells, prepared essentially as described by Adam et al. (Adam et al., 1990), were used for in vitro nuclear import assays according to Jäkel and Görlich (Jäkel and Görlich, 1998). Import mixtures contained an energy-regenerating system consisting of the following components: $0.5 \mathrm{mM}$ ATP, $0.5 \mathrm{mM}$ GTP, $10 \mathrm{mM}$ creatine 

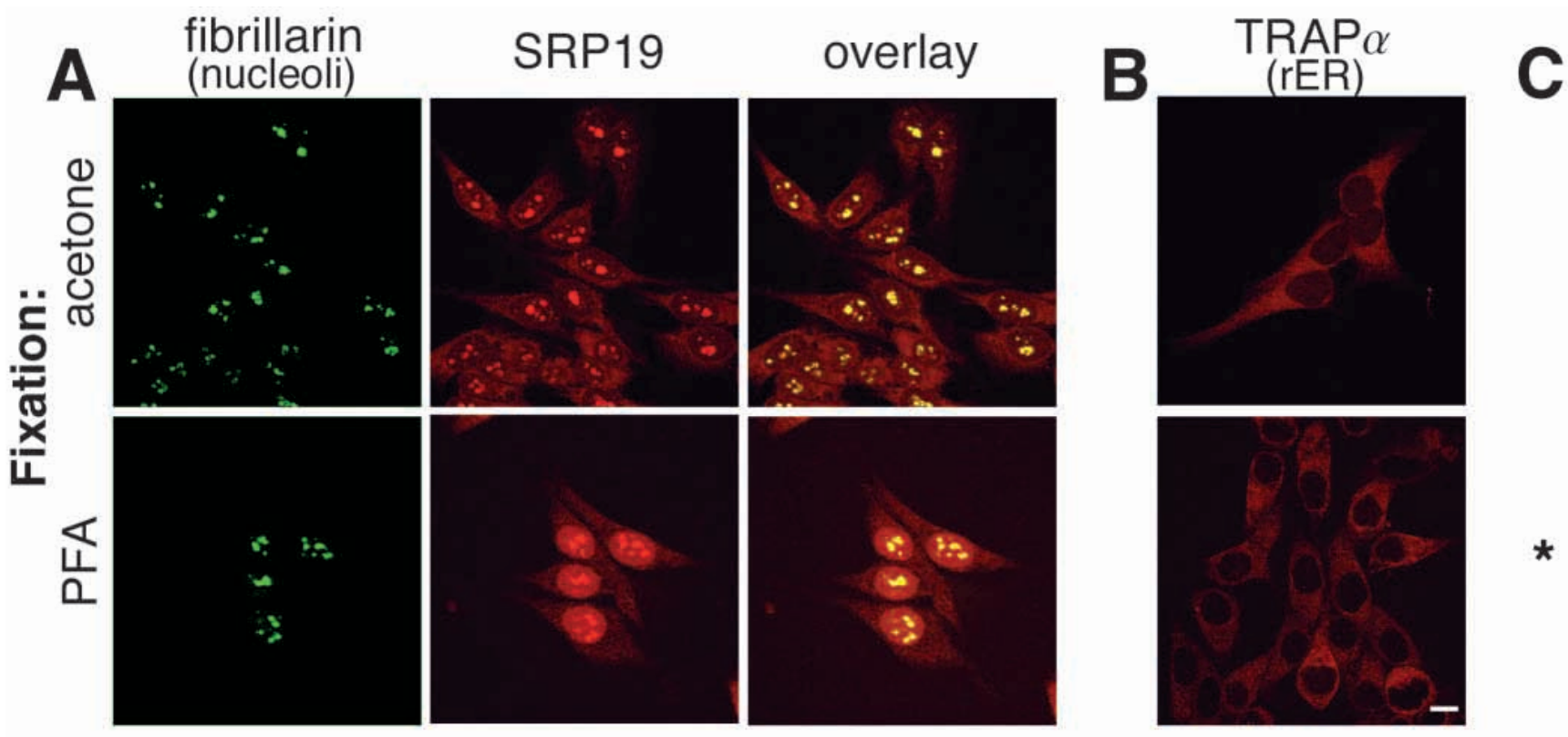

Fig. 1. Endogenous SRP19 is localized to the nucleus and the nucleolus. (A,B) SRP19 in HeLa cells was detected using indirect immunofluorescence followed by confocal microscopy (see Materials and Methods). Antibodies against fibrillarin and TRAP $\alpha$ (Görlich et al., 1990) were used as controls for nucleolar and rough endoplasmic reticulum subcellular staining. SRP19 was found to be prominent in the nucleoli and in the nucleoplasm, noticeable especially in the paraformaldehyde-fixed cells. Images were collected using the $63 \times$ oil objective of a Leica DM IRB/E microscope and analyzed with Leica TCS NT software. Bar, $10 \mu \mathrm{m}$. (C) A western blot showing that the anti-SRP19 antibody at 1:2000 dilution detected only SRP19 (*) in a total HeLa cell lysate.

phosphate and $50 \mu \mathrm{g} / \mathrm{ml}$ creatine kinase. The Ran mix constituents were $3 \mu \mathrm{M}$ RanGDP, $0.3 \mu \mathrm{M}$ RanBP1, $0.2 \mu \mathrm{M}$ Schizosaccharomyces pombe Rnalp (Ran GTPase-activating protein) and $0.4 \mu \mathrm{M}$ NTF2 (each final concentrations). Import buffers for HIS 6 -SRP19 and 4zrpL23a contained $20 \mathrm{mM}$ potassium phosphate, $\mathrm{pH} 7.2,5 \mathrm{mM}$ magnesium acetate, $0.5 \mathrm{mM}$ EGTA and $250 \mathrm{mM}$ sucrose with 140 $\mathrm{mM}$ potassium acetate for $\mathrm{HIS}_{6}$-SRP19 or $200 \mathrm{mM}$ potassium acetate for $4 \mathrm{z}-\mathrm{rpL} 23 \mathrm{a}$. Import assays were performed without addition of a cytosol extract, so that import was dependent on addition of specific transport factors and Ran.

\section{RESULTS}

\section{Subcellular localization of endogenous SRP19}

Signal recognition particle protein 19 is the only SRP protein that binds in vitro to SRP RNA independently of other SRP proteins (Lingelbach et al., 1988; Lütcke, 1995); thus, it is possible that SRP19 initiates assembly of the particle in vivo. As indicated above, SRP appears to assemble in the nucleus, making SRP19 a good candidate for examining the mechanism of nuclear import of SRP proteins. Indeed, an SRP19-GFP fusion localized to the nucleus in transiently transfected animal cells (Politz et al., 2000) and Sec65p, the yeast SRP19 homologue, was also found in the nucleus (Ciufo and Brown, 2000; Grosshans et al., 2001). Therefore, we raised an antibody against recombinant human SRP19 protein and examined the steady-state distribution of endogenous SRP19 in HeLa cells. Immunoblotting showed that the SRP19 antibody detected only a single protein in a HeLa cell extract (Fig. 1C). Fig. 1A,B shows the results for immunostaining of HeLa cells. In cells fixed either with acetone or paraformaldehyde and stained with the SRP19 antibody, we observed a diffuse cytoplasmic signal, which probably represents SRP19 assembled into mature SRP, and staining within the nucleoplasm. In particular, the antibody gave intense staining of nuclear patches, suggesting that SRP19 accumulates in nucleoli. As a control for nucleolar staining, we used a monoclonal antibody against fibrillarin, an abundant nucleolar protein associated with small nucleolar RNAs (Maxwell and Fournier, 1995). Merging of the fibrillarin and SRP19 images produced an exact overlap between the two antibody stains, indicating that endogenous SRP19 is indeed located in the nucleoli. Thus, we conclude that SRP19 is located within the nucleoplasm and nucleolus, consistent with nuclear assembly of SRP.

\section{Interactions between SRP19 and nuclear transport receptors}

Having established that endogenous SRP19 is present in the nucleus, we next wanted to elucidate the mechanism of SRP19 nuclear import. Initial experiments (not shown) revealed that SRP19 import into nuclei of permeabilized cells occurred in the presence of cytosolic extracts and that this import required RanGTP (necessary for recycling of transport receptors). This was the expected result if SRP19 import is mediated by one or more members of the importin $\beta$ superfamily of transport receptors. To identify candidate import receptors for SRP19, we incubated immobilized SRP19 with a HeLa cell extract in the presence and absence of RanQ69L[GTP]. (RanQ69L is a Ran mutant that remains GTP-bound in the presence of the Ran GTPase-activating protein RanGAP1 (Bischoff et al., 1994)). As a positive control, we immobilized human ribosomal protein L23a, whose interaction with a number of import receptors has been described (Jäkel and Görlich, 1998). Proteins in the extract that bound SRP19 and rpL23a were then identified by immunoblotting. As shown in Fig. 2, SRP19 recovered importin $\beta$, transportin, importin 5 , importin 7 and 


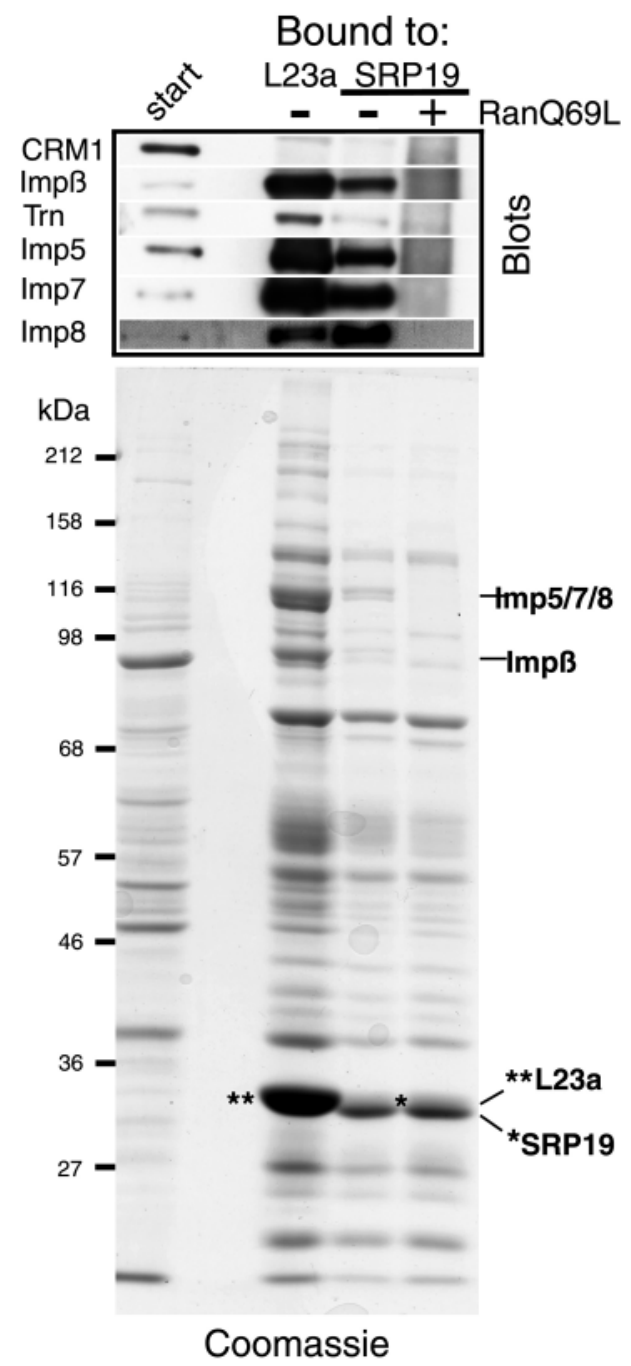

Fig. 2. Interaction of SRP19 with nuclear transport receptors. Recombinant SRP19 and rpL23a, fused to two tandem z-tags (IgGbinding domain of protein A), were immobilized on IgG-sepharose and tested for binding of transport receptors from a HeLa cell extract. Where indicated, $10 \mu \mathrm{M}$ RanQ69L[GTP] was added. RanQ69L is a GTPase-deficient Ran mutant that remains GTP-bound in the presence of cytoplasmic Ran GTPase-activating protein (RanGAP1) (Bischoff et al., 1994). After extensive washing, bound proteins were eluted, precipitated, and analyzed by SDS-PAGE, followed by immunoblotting with specific antibodies (top) or by Coomassie blue staining (bottom). Load in the bound fractions corresponds to $15 \times$ the starting material.

importin 8 present in the HeLa extract. Binding of SRP19 to these transport receptors appeared to be specific, as the interactions were abolished by the addition of RanQ69L[GTP]. Similarly, rpL23a bound importin $\beta$, transportin, importin 5 and importin 7, as demonstrated previously (Jäkel and Görlich, 1998). Additionally, rpL23a recovered importin 8 from the extract. By contrast, in this assay neither SRP19 nor rpL23a bound the exportin CRM1. Also, interactions between SRP19 and the candidate receptors (importin $\beta$, transportin, importin 5 , importin 7 and importin 8) could be reproduced using recombinant transport receptors (Fig. 3), suggesting that the binding observed in HeLa extracts was direct and not mediated by one or more additional factors present in the extracts.

\section{Characterization of SRP19 in vitro nuclear import}

Having identified importin $\beta$, transportin and importins 5, 7 and 8 as candidate receptors, we next tested whether any of these receptors could mediate nuclear import of SRP19. To characterize functionally the import receptors identified in binding assays, we carried out in vitro nuclear import assays using digitonin-permeabilized HeLa cells (Adam et al., 1990). The substrates for import were fluorescent-labeled recombinant human his-tagged SRP19 and, as a control, 4ztagged human ribosomal protein L23a (the $\mathrm{z}$-tag is the IgGbinding domain of protein A). When permeabilized cells were incubated with either SRP19 or rpL23a in buffer alone, neither protein showed any significant nuclear localization (Fig. 4A). However, in the presence of either transportin or purified importin 8 (Fig. 4D,G), considerable nuclear accumulation of SRP19 occurred. The imported SRP19 was observed in both the nucleoplasm and nucleolus; nucleolar accumulation of SRP19 in import assays was confirmed with the anti-fibrillarin antibody referred to above (data not shown). In the presence of the other import factors that bound SRP19 in a HeLa cell extract (importin $\beta$, transportin, importin 5 and importin 7), some import also occurred. However, in these cases, import appeared to be less efficient compared to transportin and importin 8, as essentially all of the SRP19 that was imported by the other factors was confined to the nucleoli and nucleolar staining was less intense overall. Similarly, importin $\beta$, transportin, importin 5 and importin 7 efficiently imported rpL23a as expected from a previous study (Jäkel and Görlich, 1998), whereas importin 8 was relatively inefficient in bringing about nuclear import of rpL23a.

\section{DISCUSSION}

In this report we have demonstrated that the $16.5 \mathrm{kDa}$ protein subunit of the mammalian signal recognition particle SRP19 is efficiently imported into the nucleus in vitro by at least two members of the importin $\beta$ family of nuclear transport receptors, importin 8 and transportin. Both receptors produced both nucleoplasmic and nucleolar accumulation of SRP19. In addition to importing SRP19 into the nucleus, importin 8 and transportin were recovered by SRP19 from a total cell lysate; typical of all importins, recovery was abolished by RanGTP, confirming that binding was specific. Importin 8 (RanBP8) was identified previously as a RanGTP-binding protein that also bound the NPC (Görlich et al., 1997). However, although it displayed properties of a nuclear transport receptor, no cargo had been associated previously with importin 8 . Our results establish importin 8 as a nuclear transport receptor and identify SRP19 as one of its substrates. In addition, SRP19 expands the inventory of RNA-binding proteins imported by transportin, first identified as the import receptor for the hnRNP A1 protein and since found to import other hnRNP proteins and some ribosomal proteins (Pollard et al., 1996; Fridell et al., 1997; Siomi et al., 1997; Jäkel and Görlich, 1998). Also, like ribosomal proteins and histones, SRP19 expands the list of proteins small enough to diffuse freely through the NPC but which nevertheless engages one or more transport receptors to enter the nucleus.

Signal recognition particle protein 19 also bound, in a RanGTP-sensitive manner, to importin $\beta, 5$ and 7 present in a 
Fig. 3. Transport receptors bind directly to SRP19 in a RanGTP-regulated manner. A GST-SRP19 fusion protein was immobilized on glutathione-sepharose and incubated with purified nuclear transport receptors, with and without RanQ69L[GTP] as described in Materials and Methods. After washing, bound proteins were eluted with SDS sample buffer and analyzed by SDSPAGE. (A) Proteins that bound to GST-SRP19 in the presence (+) and absence (-) of RanQ69L[GTP]. Note that binding of all receptors to SRP19 was greatly reduced in the presence of RanQ69L[GTP]. (B) Purified receptors, in the same order as in $\mathrm{A}$, loaded as reference samples. The asterisk indicates GST-SRP19.
A

Imp $\beta$ Trn Imp5 Imp7 Imp8

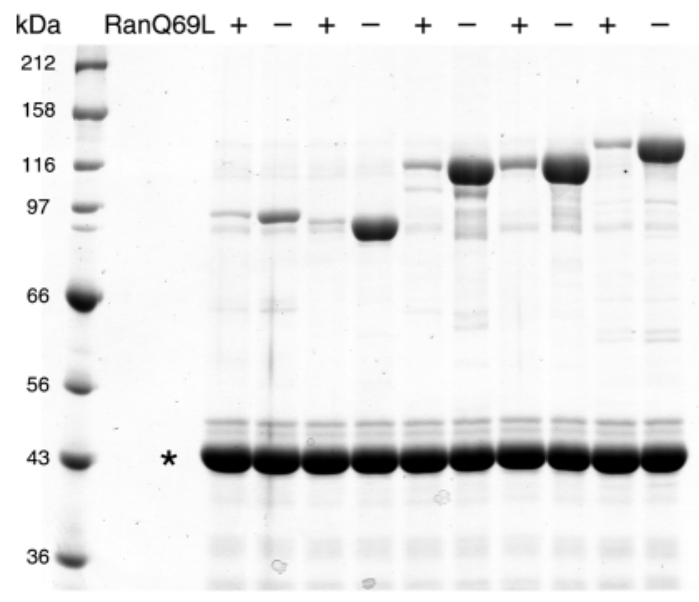

$\begin{array}{lllll}\beta & \mathrm{T} & 5 & 7 & 8\end{array}$

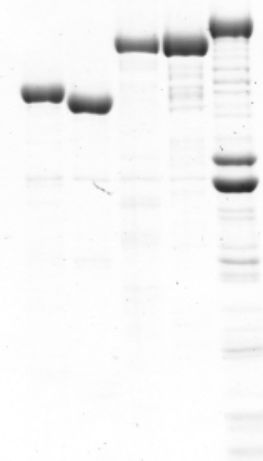

HeLa cell lysate and as purified recombinant proteins; however, these other receptors appeared to promote less nuclear import of SRP19 compared with importin 8 and transportin, as only weak nucleolar fluorescence was observed in the presence of these other receptors. Similarly, ribosomal protein L23a recovered importin 8 from the cell lysate, in a RanGTP-sensitive manner, yet importin 8 was considerably less efficient in importing rpL23a compared with other transport receptors. In yeast some ribosomal proteins are preferentially transported by one receptor but will associate
Fig. 4. SRP19 is imported into the nucleus by importin 8 and transportin. Recombinant human rpL23a or human SRP19 were purified, labeled with fluorophores and used as substrates $(2 \mu \mathrm{M}$ final concentration) for import into the nuclei of permeabilized HeLa cells. Import receptors were also used at $2 \mu \mathrm{M}$, except importin $\alpha$ (imp $\alpha$ ) and importin 8 (imp 8), which were both at $4 \mu \mathrm{M}$. Reactions were stopped by fixation after 10 minutes for SRP19 and 25 minutes for rpL23a and analyzed by confocal microscopy. As previously reported, rpL23a could be imported by any of four transport receptors: importin $\beta$ $(\mathrm{imp} \beta ; \mathrm{C})$, transportin (trn; D), importin 5 (imp5; E), and importin 7 (imp7; F) (Jäkel and Görlich, 1998). SRP19 import was most efficient with importin 8 (imp8; G); however, transportin also mediated nuclear import of SRP19 (D). All images were collected and analyzed as described in Fig. 1. Bar, $10 \mu \mathrm{m}$.

\section{Import of}
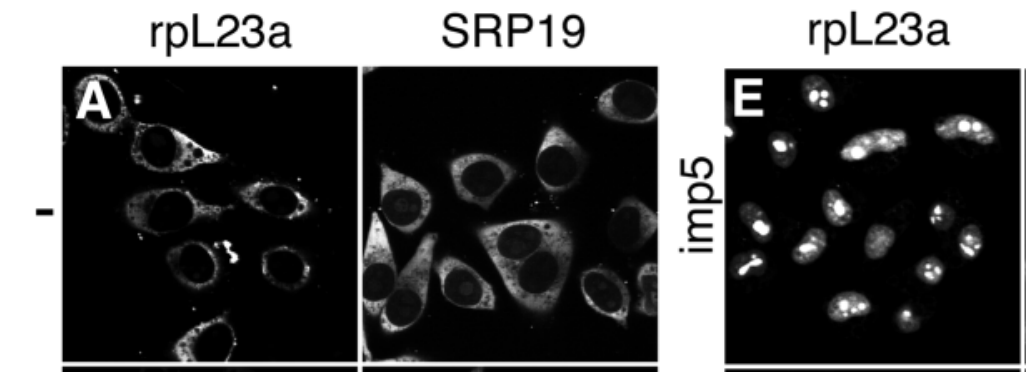

SRP19
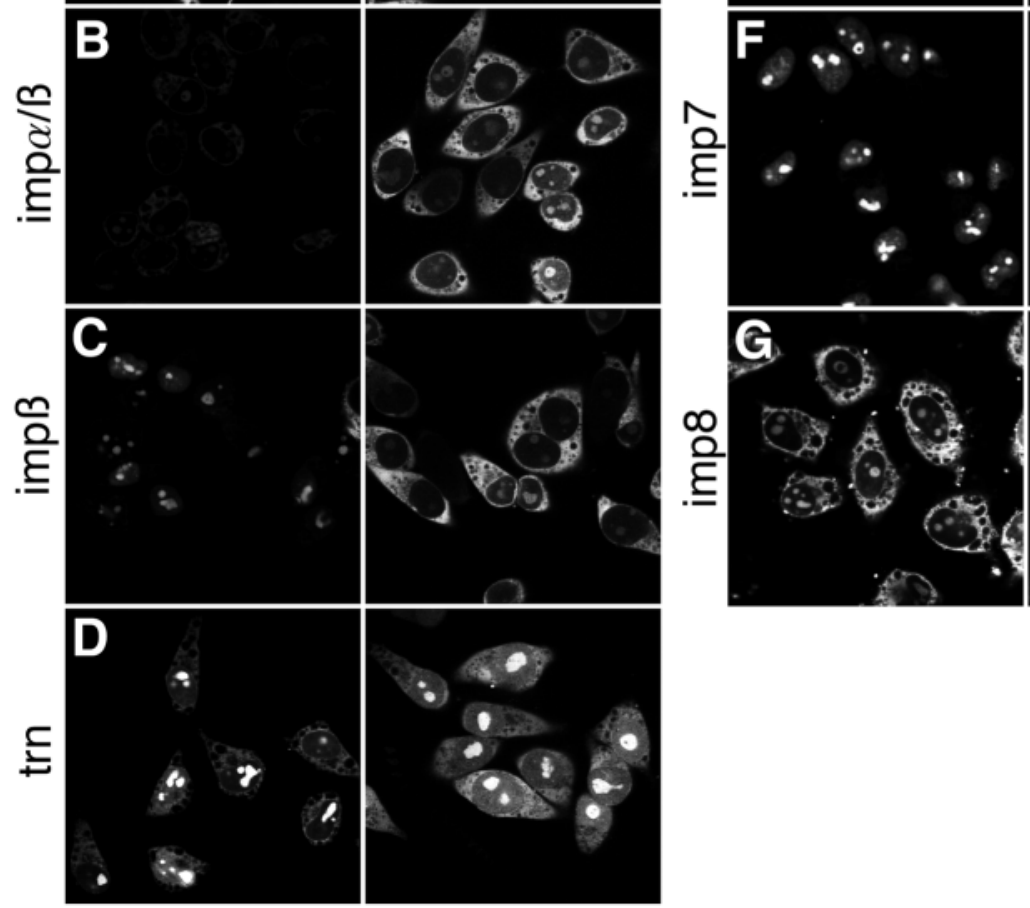
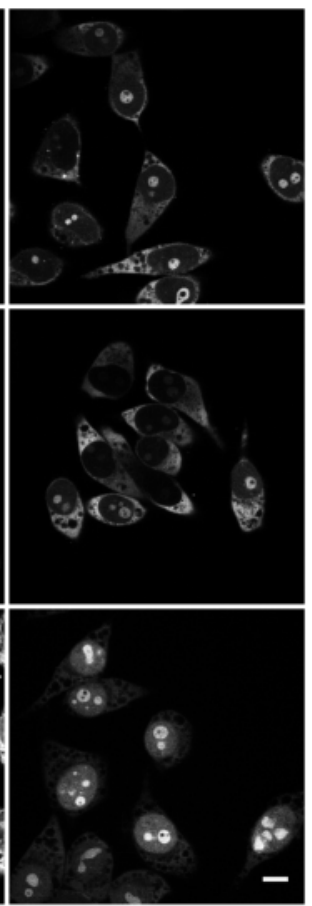
with a second receptor of lower affinity when the primary receptor is absent (Rout et al., 1997). Clearly our results do not establish which transport receptor or receptors represent the principal import pathway of SRP19 in vivo. Although importin 8 and/or transportin would appear to be the most likely candidates based on efficiency, by analogy to yeast ribosomal proteins, importin $\beta, 5$ and/or 7 may constitute backup pathways for SRP19 import. Grosshans et al. (Grosshans et al., 2001) reported that nuclear localization of Sec65p, the yeast homolog of SRP19, was greatly reduced in a mutant defective in importin $\alpha$, an adapter that bridges importin $\beta$ and cargo having so-called classical nuclear localization sequences. However, inclusion of importin $\alpha$ with importin $\beta$ in our in vitro import assays did not produce any increased nuclear import of SRP19 beyond the minimal import seen with importin $\beta$ alone. Grosshans et al. (Grosshans et al., 2001) also reported that nuclear localization of Sec65p was affected to some degree in mutants defective in several other import receptors, including Pse1p and Kap123p/Yrb4p, which are related to mammalian importin 5 .

Signal recognition particle protein 19 is one of many proteins imported into the nucleus by more than one member of the importin receptor family. Most yeast SRP proteins, as well as ribosomal protein L25, are imported by Pse1p and Kap123p/Yrb4p (Grosshans et al., 2001; Rout et al., 1997; Schlenstedt et al., 1997). Kap114p, Kap121p and Kap123p are involved in import of the yeast TATA-binding protein (Pemberton et al., 1999) and these same three importins, along with Kap95p (yeast importin $\beta$ ), are involved in histone $\mathrm{H} 2 \mathrm{~A}$ and H2B nuclear import (Mosammaparast et al., 2001; Mühlhäusser et al., 2001). Similarly, human rpL23a, the homologue of yeast L25, as well as human rpS7, can be imported by importin $\beta$, transportin, importin 7 and importin 5 ; human rpL5 is also imported by several receptors (Jäkel and Görlich, 1998). Having multiple receptors, it will be interesting to determine which portion of SRP19 interacts with importin 8 and transportin. Although importin 8 and transportin do not share any significant similarity other than their N-terminal RanGTP-binding domains, this lack of homology does not necessarily mean that the two receptors bind different regions of SRP19. The four receptors that bind rpL23a share $<15 \%$ sequence identity yet all four interact with the same segment of rpL23a, the BIB domain (residues 32-74) (Jäkel and Görlich, 1998). Also, transportin has at least two distinct, nonoverlapping cargo binding sites, one for M9-containing substrates and another for those that contain the BIB domain (Pollard et al., 1996; Jäkel and Görlich, 1998). Sequence comparisons have not revealed any significant similarity between SRP19 and either M9 or BIB although, given that SRP19 and BIB are highly basic, it seems more likely that SRP19 interacts with the BIB-binding site of transportin.

Finally, immunostaining of fixed HeLa cells revealed endogenous SRP19 not only in the cytoplasm, where mature $\mathrm{SRP}$ resides, but also in the nucleoplasm and the nucleolus. A previous study using another polyclonal SRP19 antibody detected SRP19 only in the cytoplasm (Bovia et al., 1995). The basis for this difference is not known, although a different fixative was used in the previous study. Our results clearly demonstrate that SRP19 is a nuclear protein in animal cells and support a model in which mammalian SRP assembles in the nucleus, as is the case for yeast (Ciufo and Brown, 2000;
Grosshans et al., 2001). Politz et al. (Politz et al., 2000) also provided evidence for nuclear assembly of SRP, as they observed both nucleoplasmic and nucleolar localization of GFP fusions of SRP19, SRP68 and SRP72 in transiently transfected cells. Importantly, our immunolocalization results confirm the observations of Politz et al. in a way that is not subject to potential mislocalization arising from overexpression of proteins with high affinities for RNA. The nucleolar localization of SRP proteins is especially interesting. Using in situ hybridization, Politz et al. have reported that SRP RNA is found in the nucleolus. This observation, coupled with the nucleolar localization of SRP proteins, suggests that at least one stage in SRP assembly occurs in the nucleolus, a structure previously assumed to be host to only ribosome assembly. Precursor tRNAs, the RNA and protein subunits of RNase P, and tRNA base modification enzymes have also been recently localized in the nucleolus (Carmo-Fonseca et al., 2000; Pederson and Politz, 2000). This, in combination with our results, suggests that the nucleolus is not only the assembly site for ribosomes but is involved in assembly and processing of other RNAs and ribonucleoproteins.

We thank Thoru Pederson for the anti-fibrillarin antibody, Petra Schwarzmaier for excellent technical help, in particular for affinity purification of antibodies, Ulrike Kutay for insight and critical reading of the manuscript, and the members of the Görlich lab, Stefan Jäkel, Gerd Lipowsky, Katharina Ribbeck and Froso Paraskeva for their invaluable expertise and stimulating discussions. This work was supported by grants from the Deutsche Forschungsgemeinschaft (SFB 352 to D.G.), from the Human Frontier Science Programme Organisation (grant RG0198/1998M) to D.G. and US National Science Foundation grant MCB-9817104 to H.M.F.

\section{REFERENCES}

Adam, S. A., Sterne Marr, R. and Gerace, L. (1990). Nuclear protein import in permeabilized mammalian cells requires cytoplasmic factors. J. Cell Biol. 111, 807-816.

Batey, R. T., Rambo, R. P., Lucast, L., Rha, B. and Doudna, J. A. (2000). Crystal structure of the ribonucleoprotein core of the signal recognition particle. Science 287, 1232-1239.

Bischoff, F. R., Klebe, C., Kretschmer, J., Wittinghofer, A. and Ponstingl, H. (1994). RanGAP1 induces GTPase activity of nuclear ras-related Ran. Proc. Natl. Acad. Sci. USA 91, 2587-2591.

Bovia, F., Fornallaz, M., Lefters, H. and Strub, K. (1995). The SRP9/14 subunit of the signal recognition particle (SRP) is present in more than 20 -fold excess over SRP in primate cells and exists primarily free but also in complex with small cytoplasmic Alu RNAs. Mol. Cell Biol. 6, 471484.

Carmo-Fonseca, M., Mendes-Soares, L. and Campos, I. (2000). To be or not to be in the nucleolus. Nat. Cell Biol. 2, E107-E112.

Ciufo, L. F. and Brown, J. D. (2000). Nuclear export of yeast signal recognition particle lacking Srp54p by the Xpo1p/Crm1p NES-dependent pathway. Curr. Biol. 10, 1256-1264.

Fridell, R. A., Truant, R., Thorne, L., Benson, R. E. and Cullen, B. R. (1997). Nuclear import of hnRNP A1 is mediated by a novel cellular cofactor related to karyopherin-beta. J. Cell Sci. 110, 1325-1331.

Görlich, D. and Kutay, U. (1999). Transport between the cell nucleus and the cytoplasm. Annu. Rev. Cell Dev. Biol. 15, 607-660.

Görlich, D., Prehn, S., Hartmann, E., Herz, J., Otto, A., Kraft, R., Wiedmann, M., Knespel, S., Dobberstein, B. and Rapoport, T. A. (1990). The signal sequence receptor has a second subunit and is part of a translocation complex in the endoplasmic reticulum as probed by bifunctional reagents. J. Cell Biol. 111, 2283-2294.

Görlich, D., Prehn, S., Laskey, R. A. and Hartmann, E. (1994). Isolation of a protein that is essential for the first step of nuclear protein import. Cell 79, 767-778. 
Görlich, D., Vogel, F., Mills, A. D., Hartmann, E. and Laskey, R. A. (1995). Distinct functions for the two importin subunits in nuclear protein import. Nature 377, 246-248.

Görlich, D., Pante, N., Kutay, U., Aebi, U. and Bischoff, F. R. (1996). Identification of different roles for RanGDP and RanGTP in nuclear protein import. EMBO J. 15, 5584-5594.

Görlich, D., Dabrowski, M., Bischoff, F. R., Kutay, U., Bork, P., Hartmann, E., Prehn, S. and Izaurralde, E. (1997). A novel class of RanGTP binding proteins. J. Cell Biol. 138, 65-80.

Grosshans, H., Deinert, K., Hurt, E. and Simos, G. (2001). Biogenesis of the signal recognition particle (SRP) involves import of SRP proteins into the nucleolus, assembly with SRP-RNA, and Xpo1p-mediated export. $J$. Cell Biol. 153, 745-761.

He, X. P., Bataillé, N. and Fried, H. M. (1994). Nuclear export of signal recognition particle RNA is a facilitated process that involves the Alu sequence domain. J. Cell Sci. 107, 903-912.

Henry, K. A., Zwieb, C. and Fried, H. M. (1997). Purification and biochemical characterization of the 19-kDa signal recognition particle RNAbinding protein expressed as a hexahistidine-tagged polypeptide in Escherichia coli. Protein Expres. Purif. 9, 15-26.

Izaurralde, E., Kutay, U., von Kobbe, C., Mattaj, I. W. and Görlich, D. (1997). The asymmetric distribution of the constituents of the Ran system is essential for transport into and out of the nucleus. EMBO J. 16, 65356547.

Jäkel, S. and Görlich, D. (1998). Importin beta, transportin, RanBP5 and RanBP7 mediate nuclear import of ribosomal proteins in mammalian cells. EMBO J. 17, 4491-4502.

Kutay, U., Izaurralde, E., Bischoff, F. R., Mattaj, I. W. and Görlich, D. (1997). Dominant-negative mutants of importin-beta block multiple pathways of import and export through the nuclear pore complex. EMBO J. 16, 1153-1163.

Lingelbach, K., Zwieb, C., Webb, J. R., Marshallsay, C., Hoben, P. J., Walter, P. and Dobberstein, B. (1988). Isolation and characterization of a cDNA clone encoding the $19 \mathrm{kDa}$ protein of signal recognition particle (SRP): expression and binding to 7SL RNA. Nucleic Acids Res. 16, 94319442.

Luirink, J. and Dobberstein, B. (1994). Mammalian and Escherichia coli signal recognition particles. Mol. Microbiol. 11, 9-13.

Lütcke, H. 1995. Signal recognition particle (SRP), a ubiquitous initiator of protein translocation. Eur. J. Biochem. 228, 531-550.
Maxwell, E. S. and Fournier, M. J. (1995). The small nucleolar RNAs. Annu. Rev. Biochem. 35, 897-934.

Mosammaparast, N., Jackson, K. R., Guo, Y., Brame, C. J., Shabanowitz, J., Hunt, D. F. and Pemberton, L. F. (2001). Nuclear import of histone $\mathrm{H} 2 \mathrm{~A}$ and $\mathrm{H} 2 \mathrm{~B}$ is mediated by a network of karyopherins. J. Cell Biol. 153, 251-262.

Mühlhäusser, P., Müller, E.-C., Otto, A. and Kutay, U. (2001). Multiple pathways contribute to nuclear import of core histones. EMBO Rep. 2, 690696.

Nakielny, S. and Dreyfuss, G. (1999). Transport of proteins and RNAs in and out of the nucleus. Cell 99, 677-690.

Pederson, T. and Politz, J. C. (2000). The nucleolus and the four ribonucleoproteins of translation. J. Cell Biol. 148, 1091-1095.

Peluso, P., Herschlag, D., Nock, S., Freymann, D. M., Johnson, A. E. and Walter, P. (2000). Role of 4.5S RNA in assembly of the bacterial signal recognition particle with its receptor. Science 288, 1640-1643.

Pemberton, L. F., Rosenblum, J. S. and Blobel, G. (1999). Nuclear import of the TATA-binding protein: mediation by the karyopherin Kap $114 \mathrm{p}$ and a possible mechanism for intranuclear targeting. J. Cell Biol. 145, 1407-1417.

Politz, J. C., Yarovoi, S., Kilroy, S. M., Gowda, K., Zwieb, C. and Pederson, T. (2000). Signal recognition particle components in the nucleolus. Proc. Natl. Acad. Sci. USA 97, 55-60.

Pollard, V. W., Michael, W. M., Nakielny, S., Siomi, M. C., Wang, F. and Dreyfuss, G. (1996). A novel receptor-mediated nuclear protein import pathway. Cell 86, 985-994.

Rout, M. P., Blobel, G. and Aitchison, J. D. (1997). A distinct nuclear import pathway used by ribosomal proteins. Cell 89, 715-725.

Schlenstedt, G., Smirnova, E., Deane, R., Solsbacher, J., Kutay, U., Görlich, D., Ponstingl, H. and Bischoff, F. R. (1997). Yrb4p, a yeast RanGTP-binding protein involved in import of ribosomal protein L25 into the nucleus. EMBO J. 16, 6237-6249.

Siomi, M. C., Eder, P. S., Kataoka, N., Wan, L., Liu, Q. and Dreyfuss, G. (1997). Transportin-mediated nuclear import of heterogeneous nuclear RNP proteins. J. Cell Biol. 138, 1181-1192.

Yoneda, Y., Hieda, M., Nagoshi, E. and Miyamoto, Y. (1999). Nucleocytoplasmic protein transport and recycling of Ran. Cell Struct. Funct. 24, 425-433.

Young, P. and Gautel, M. (2000). The interaction of titin and $\alpha$-actinin is controlled by a phospholipid-regulated intramolecular pseudoligand mechanism. EMBO J. 19, 6331-6340. 